\title{
INVESTIGATION OF EMS (ELECTROMAGNETIC STIRRING) CONDITIONS DURING CONTINUOUS CASTING OF HIGH-CARBON STEELS
}

\author{
Artur HUTNY, Marek WARZECHA, Włodzimierz DERDA \\ Czestochowa University of Technology, Faculty of Production Engineering and Materials Technology, \\ Czestochowa, Poland, EU, hutny@wip.pcz.pl
}

https://doi.org/10.37904/metal.2019.794

\begin{abstract}
Modern devices for continuous casting (cc.) of steel - despite the shape of cross-section of cast billets, are equipped with electromagnetic systems for stirring liquid core inner the solidifying steel shell. Depending on the grade of cast steels, requirements for isotropy of chemical composition and properties along transverse and longitudinal cross-section of cc. billets, there are applied various schemes in placing systems inducing motions (rotation) of the liquid core.
\end{abstract}

Based on the analysis of samples after etching, being cut out as continuous casting billets with square crosssections, the following was stated: the surface of the equiaxed crystal zone, values of overheating and the total surface - on which internal structural defects can be observed in continuous casting of billets.

Keywords: Steel, electromagnetic stirring, continuous casting, defects of billets

\section{INTRODUCTION}

Control of the electromagnetic stirring (EMS) system, despite its position, is carried out by changing two parameters of current supplying the coil system of the inductor: the intensity of current I and its frequency $f$. In exceptional cases and to significantly limited extent, in some designs of continuous casting (cc.) devices, the location of coils in the inductor can be changed in relation to walls of the crystallizer (M-EMS) or to solidifying steel shell (EMS - S, EMS - F), when adjustments of current parameters does not cause expected changes. It could therefore be stated that controlling the intensity of liquid core rotation movements inside the solidifying steel shell in order to achieve the optimum metallurgical effect is a very simple task, fully mastered. In practice, selection of electromagnetic conditions for stirring is one of the most difficult tasks in the field of controlling the cc. process.

By selecting values of current intensity (usually at constant frequency of current for a given cross-section of billets), following items should be taken into consideration, namely: the method of casting (open stream or in ceramic sheaths), steel grade being casted, type of protection powder in the crystallizer, shape and size of the cross-section of billets, thickness of wall of cooper pipe in the mould, the depth of pouring the ceramic nozzle into liquid steel in the mould, the degree of overheating steel above the liquidus temperature, etc. Such plurality of factors affecting determination of operational values of the intensity of current supplying the EMS system, requires selecting values of a number of coefficients correcting the maximum intensity $I_{\max }$, foreseen for a given system design and considering the impact of the above-mentioned characteristics of continuous casting.

The subject reference sources point solely on general principles of selecting parameters of electric power supplying the EMS systems; so it is required to specify a number of coefficients, the presence of which will facilitate the continuous casting technology of particular steel grades and ingot shapes in determining appropriate values of the supply current $I_{\max }$ and current frequency $f$, and this is the main objective of this work.

\section{THEORETICAL JUSTIFICATION OF RESEARCH STUDIES ON ELECTROMAGNETIC STIRRING OF STEEL DURING CONTINUOUS CASTING OF BILLETS WITH SQUARE CROSS-SECTION}

Electromagnetic stirrer, consisting of a set of copper coils, being supplied with alternating electrical current that surround cc. billets and placed in the water-cooled jacket, induces rotating magnetic field, which in the volume 
of liquid metal - inner the solidified shroud - generates on the basis of induction, the mechanical torque causing rotation of the metal.

To evaluate the effective electric field penetration depth into particular layers - and thus, to facilitate selection of stirrer construction for certain dimensions of continuously cast billets, there is given the relationship [2] making dependent from the current frequency $f$ and magnitudes characterizing layers being penetrated by the magnetic flux, adopting the form of:

$\delta_{C}=150 \sqrt{\frac{1}{\sigma \cdot f \cdot \mu}}(\mathrm{cm})$

where: $\sigma$ - specific electrical conductivity $\left(\Omega \mathrm{m}^{-1}\right)$

$f$ - frequency of current supplying the stirrer $(\mathrm{Hz})$

$\mu$ - magnetic permeability of the material $(\mathrm{H} / \mathrm{m})$

By applying the data on conductivity of copper and liquid steel [3] for the purpose of this study, there were determined theoretical dependencies of functions between magnetic field penetration depth for copper and liquid steel and the frequency of current supplying the stirrer, which were illustrated graphically in Figures 1 and 2.

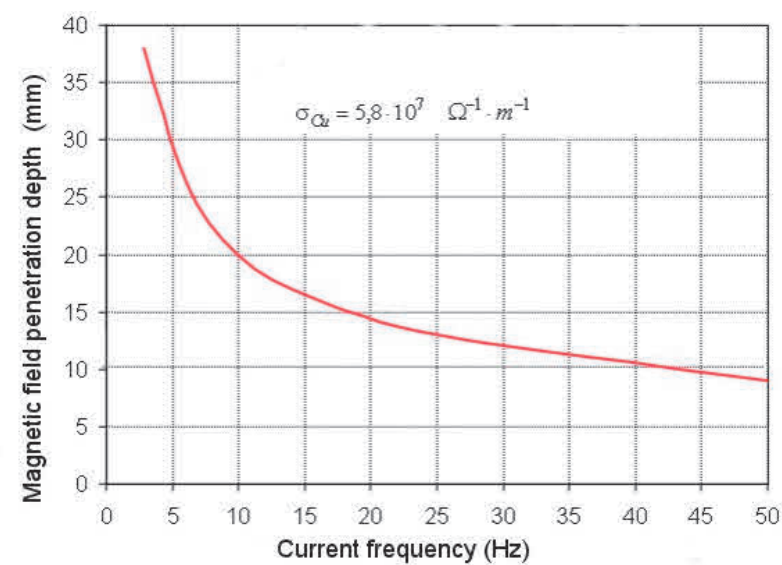

Figure1 Magnetic field penetration depth in cooper according to current frequency supplying the stirrer

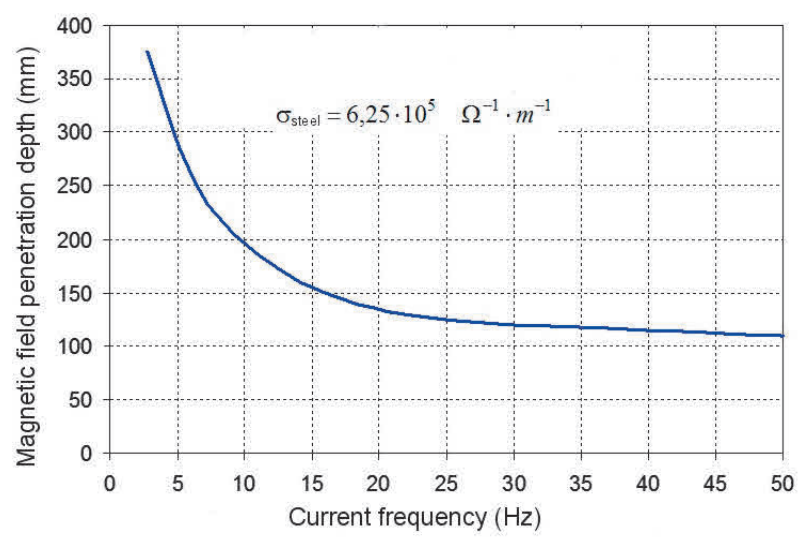

Figure 2 Magnetic field penetration depth in liquid steel according to current frequency supplying the stirrer

As it can be observed in Figure 1 and Figure 2, the magnetic field penetration depth for both, the copper layer and liquid steel decreases with an increase of the frequency of current supplying the stirrer; although, in both of the analysed cases, these dependencies refer to various values of magnetic field penetration depths into the corresponding layer. This regularity will facilitate determination of values of coefficients correcting the values of stirrer's operating current during casting of a specific steel grade and shape/size of the cc. ingot.

\section{THE EFFECTS OF ELECTROMAGNETIC STIRRING ON PROPERTIES AND CRYSTAL STRUCTURE OF BILLETS}

Taking into account the mechanism and conditions for billets solidification, it should be noted that regardless the number and location of the stirrer, the evoked rotation of liquid phase acts - in each case - on solidification interface of billets. As a result of this interaction, depending on the intensity of metal movements (values of selected parameters of current supplying the stirrer) and casting conditions, following outcomes can be gained:

- $\quad$ increase in the share of equiaxed crystals at the expense of reduction of scope and size of columnar crystals and highly complex dendrites, 
- $\quad$ eliminate adverse effects of the so-called transcrystallization, particularly in high alloy steels containing chromium,

- decrease the number of defects in billets, such as surface cracks, inner cracks and pinholes,

- $\quad$ limit segregation of elements, mainly carbon, sulphur and phosphorus along the cross-section of a billets,

- $\quad$ reduce axial porosity and the size of inner shrinkage cavity,

- $\quad$ limit the anisotropy of non-metallic inclusion distribution along he cross-section of billets [4].

It is very common in metallurgical practice that electromagnetic stirring systems are used to reduce adverse effects of continuous casting at temperature much higher than the liquidus temperature for particular steel chemical content $\left(\Delta T=T_{\text {cast. }}\right.$ - Tlliquid. $>40 \mathrm{deg}$ ). Over-temperatures of casting (overheating) lead to a series of defects in the crystal structure of billets, namely: shrinkage porosity and axial shrinkage cavity, reduced size or lack of equiaxed crystal zone, including the so-called transcrystallization, excessive segregation of elements, surface and inner defects, etc. Practical applications shows that in cases, where $\Delta T>40$ deg (billets with a high degree of overheating), M-EMS stirrers with intensified rotation (with set current at adequately high level) can mitigate - to some extend - the occurrence of defects, however, it does not exclude them totally and it may even lead to formation of other type of defects in billets, such as slag inclusions from lubricant powder added to the surface of steel in the crystallizer, failures in casting, including solidifying steel shell breaks and steel leakages, sub-surface cracks, excessive wear of ceramic components of stream covers and many others. It should be assumed that selection of EMS operational parameters for current requires subordination to proper and specified in technological principles on setting temperature of continuous casting.

\section{DETERMINING THE VALUES OF COEFFICIENTS CORRECTING CURRENT PARAMETERS OF THE MOULD EMS BY CASTING BILLETS WITH SQUARE CROSS-SECTION}

Research studies aimed at determining values of coefficients correcting the intensity of current supplying the electromagnetic stirrer of M-EMS type, depending on casting conditions, were performed by using industrial continuous casting machine, designated for casting billets with square cross-section, having the square dimensions of $130 \div 160 \mathrm{~mm}$, manufactured of carbon and low alloy steels. Evaluation of the effect of selecting M-EMS stirrer setting options, influencing the quality of crystal structure of billets and the frequency of occurrence of internal defects, was performed based on comparison of etched samples (the so-called discs) comprising the entire cross-section of the ingot with relevant models.

Table 1 List of parameters for assessing defects on the transverse surface of continuously casted billets measuring 130x130 mm at various current frequencies supplying the M-EMS stirrer for high carbon steels indicated for drawing processes

\begin{tabular}{|c|c|c|c|c|c|c|c|c|c|}
\hline \multirow{2}{*}{$\begin{array}{c}\text { Steel } \\
\text { grade }\end{array}$} & $\begin{array}{c}\text { Axial } \\
\text { shrinkage } \\
\text { cavity }\end{array}$ & $\begin{array}{c}\text { Centreline } \\
\text { porosity }\end{array}$ & $\begin{array}{c}\text { Corner } \\
\text { cracks }\end{array}$ & $\begin{array}{c}\text { Mid- } \\
\text { face } \\
\text { cracks }\end{array}$ & $\begin{array}{c}\text { Centreline } \\
\text { cracks }\end{array}$ & $\begin{array}{c}\text { Sub- } \\
\text { surface } \\
\text { cracks }\end{array}$ & $\begin{array}{c}\text { Total } \\
\text { surface } \\
\text { with } \\
\text { defects }\end{array}$ & $\begin{array}{c}\Delta \mathrm{T}, \\
\text { deg }\end{array}$ & $\begin{array}{c}\text { Current } \\
\text { intensity, } \\
\text { (A) }\end{array}$ \\
\hline A & 0 & 5.64 & 2.10 & 5.97 & 10.69 & 0 & 24.40 & 48 & 91 \\
\hline B & 0.21 & 0 & 0 & 0 & 0 & 0 & 0.21 & 37 & 92 \\
\hline C & 0.01 & 0 & 0 & 13.09 & 0 & 1.15 & 14.25 & 45 & 101 \\
\hline A & 0.08 & 0 & 12.77 & 31.47 & 20.65 & 1.05 & 66.02 & 55 & 92 \\
\hline C & 0.25 & 0 & 0 & 0 & 0 & 0 & 0.25 & 42 & 102 \\
\hline B & 0.02 & 0 & 0 & 0 & 0 & 0 & 0.02 & 40 & 93 \\
\hline D & 0 & 0.15 & 0 & 0 & 0 & 0 & 0.15 & 42 & 135 \\
\hline
\end{tabular}


Selection of the billets, from which a sample was collected, was made randomly. Objects of the analysis were defects discovered in cross-sections of 130x130 mm made of high carbon steel billets, namely: axial shrinkage cavity, centreline porosity, corner cracks, sub-surface cracks, midway cracks, midface cracks of the billets.

After making comparison of the etched structure with corresponding models (standards), there was determined the intensity (\%) of particular defects with reference to standards referring to particular types of defects identified in the cross-section of the sample. The obtained results are listed in Table 1.

$\Delta T=T_{\text {cast. }}-T_{\text {liq. }}$., degree of steel overheating; difference between average casting temperature measured in the tundish (arithmetic average taken from 3 or 4 measurements) and the liquidus temperature for chemical composition of steel being cast.

The liquidus temperature was computed based on the relationship:

Tliq., $\left[{ }^{\circ} \mathrm{C}\right]=1536.6-\alpha[\% \mathrm{C}]-8[\% \mathrm{Si}]-5[\% \mathrm{Mn}]-30[\% \mathrm{P}]-25[\% \mathrm{~S}]-1.5[\% \mathrm{Cr}]-4[\% \mathrm{Ni}]-5[\% \mathrm{Cu}]-2[\% \mathrm{Mo}]-2[\% \mathrm{~V}]$ $-5.1[\% \mathrm{Al}]$, for $0.11<[\% \mathrm{C}]<0.50$; for $0.71<[\% \mathrm{C}]<0.80$

According to the findings set out in section 2 of this research study, billets with cross-section of $130 \times 130 \mathrm{~mm}$ were casted at set constant frequency of current supplying the M-EMS stirrer of $f=8 \mathrm{~Hz}$.

Based on the collected results, summarized in Table 1, and on the photomicrographs, it can be stated that the frequency of occurrence and the size of defects in test samples collected from cross-sections of billets, as well as, the surface occupied by equiaxed crystal zone in billets are dependent on the temperature of the casting stream of liquid steel measured in tundish (degree of overheating $\Delta \mathrm{T}$ ) and also on electromagnetic stirrer operating conditions, in particular, on the value of intensity of current supplying the stirrer. These findings are confirmed by location of measurement points, presented in Figure 3.

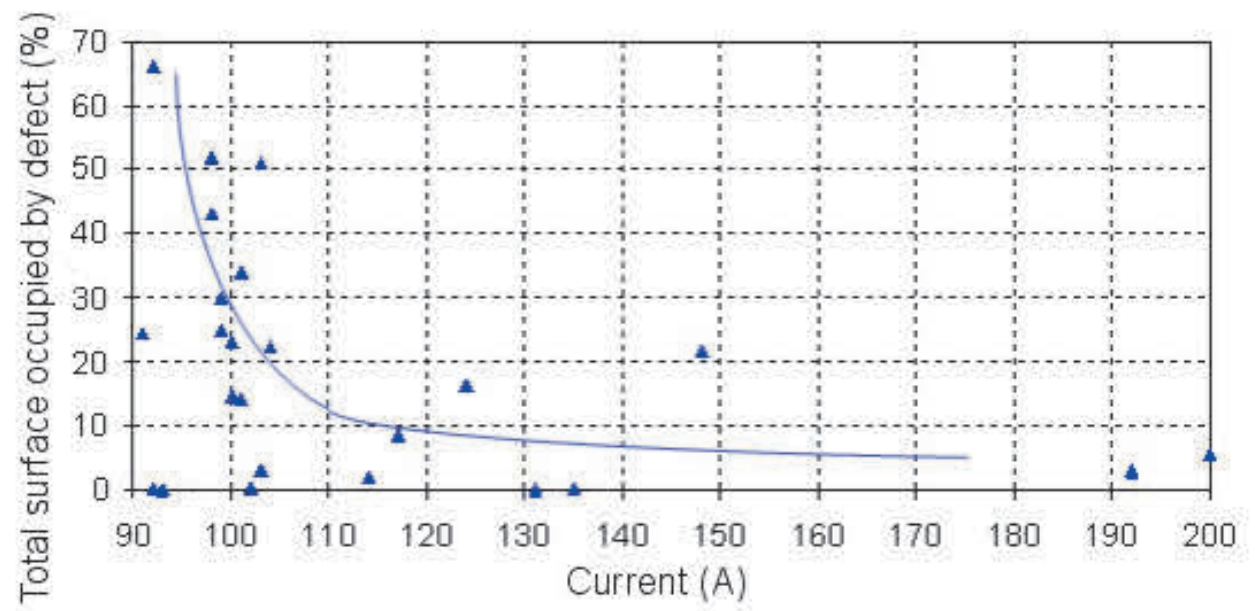

Figure 3 Dependence between the total surface occupied by defects according to standards and the intensity of current supplying the stirrer

The indicated findings demonstrate that by proper selection of parameters on supplying the M-EMS stirrer with electric power (the intensity of rotating the liquid metal in shroud) there can be limited the adverse effect of overheating the metal during continuous casting affecting the raise of defects in billets and the size of equiaxed crystal zone. When selecting parameters, namely by applying the intensity of current supplying the stirrer at a constant frequency, there should be considered metallurgical conditions of continuous casting of steel and its chemical composition. Lack of explicit formulas and dependencies describing the effect of the intensity of current supplying the stirrer on identification of structural defects of billets inclines the authors to elaborate data tailored to specific conditions based on own practices on the analysis of obtained structures of billets; and such findings requires accurate and periodic verification. 
On the basis of research material being collected, the authors recommend to apply following procedure, when entering parameter settings for electric current supplying the electromagnetic stirrer:

1) the optimum current frequency values: $8 \mathrm{~Hz}$

2) operating current intensity should be computed based on the following formula:

$I_{\text {rob }}=\varphi_{1} \cdot \varphi_{2} \cdot \varphi_{3} \cdot \varphi_{4} \cdot I_{\max }$

where: $\varphi_{1}$ - continuous casting method dependent coefficient,

$\varphi_{2}$ - billet cross-section size dependent coefficient,

$\varphi_{3}$ - carbon content in steel (liquidus temperature) dependent coefficient,

$\varphi_{4}$ - casting temperature (degree of steel overheating, $\Delta \mathrm{T}$ ) dependent coefficient,

$I_{\max }$ - rated current value that is permitted for the coil construction used in the electromagnetic stirrer $(A)$

- Value of the coefficient $\varphi 1$, depending on conditions for continuous casting:

Open stream: $\mathbf{1 . 0}$; In ceramic protection sheaths: $0.67 \div 0.70$

Using in crystallizer powders with a low melting point: $\mathbf{0 . 6 5}$

- $\quad$ Value of the coefficient $\varphi 2$, depending on the size of ingot cross-section during continuous casting: $\mathbf{0 . 8}$

- Value of the coefficient $\varphi 3$, depending on the type of steel being casted (carbon content)

$[\% \mathrm{C}] \leq 0.1-1.00 ; 0.11 \leq[\% \mathrm{C}] \leq \mathbf{0 . 5 0}-\mathbf{0 . 8 2} ; \% \mathrm{C}]>\mathbf{0 . 5 0}-\mathbf{0 . 8 6}$

- $\quad$ Value of the coefficient $\varphi 4$, depending on the degree of overheating the steel, $\Delta T$

$50-1.0 ; 45-0.93 ; 40-0.9 ; 35-0.86$

\section{FINDINGS AND CONCLUSIONS}

Based on the analysis of samples after etching, being cut out as continuously casted billets with square crosssections and diameters of $130 \times 130$, the following was stated:

1) Being determined on the basis of reference standards, the total surface - on which internal structural defects can be observed in continuously casted billets made of steel high carbon steels with drawing increases with growing degree of metal overheating $\Delta \mathrm{T}$, being designated on the basis of temperature measured in the tundish. After exceeding the specific value, the number of defects increases rapidly.

2) In a number of measured cases the determined values of overheating are excessive and they are not justified, even when they concern first melts in the sequence.

3) Value analysis of intensities of electric power supplying the M-EMS stirrer for test melts indicated that in a number of cases the value could be increased, in particular, during the casting of melts with a high degree of overheating of liquid steel. This allows for reducing in some extend the intensity of occurrence of internal defects when manufacturing billets in continuous casting.

4) There were yielded values (or their boundaries) of several coefficients correcting the nominal value of the intensity of electric power supplying the M-EMS stirrer, making capable of establishing the operating current value, while considering the metallurgical conditions occurring during the continuous casting process of the tested types of steel grades.

\section{ACKNOWLEDGEMENTS}

Acknowledgements to the National Centre for Research and Development for financial support (project No PBS2/ A5/32/2013). 


\section{REFERENCES}

[1] MAURYA, Ambrish, JHA, Pradeep. Study of fluid flow and solidification in billet caster continuous casting cold with electromagnetic stirring. Archives of Metallurgy and Materials. 2018, vol. 63, no. 1, pp.413-424.

[2] MESINA, Marian B., DE JONG, Tako Pieter Rinze, DALMIJN, Wijnand L., Improvements in separation of nonferrous scrap metals using an electromagnetic sensor, Physical Separation in Science and Engineering. 2003. vol.12, no. 2, pp.87-101.

[3] Collective work. Electromagnetic stirring applied on Continuous Casting, Danieli Rotelec, Materials from the Symposium, Poland, 22 Oct. 1993.

[4] Electromagnetic stirrers for billet and bloom continuous casting machines, Information materials, ABB Industrial System AB. 